\title{
Renda da terra e o espaço urbano capitalista contemporâneo
}

\author{
Land rent and the urban space in contemporary capitalism
}

\author{
RENAN PEREIRA ALMEIDA \\ ROBERTO LUÍS DE MELO MONTE-MÓR*
}

RESUMO: Este trabalho visa expor e discutir quais correntes do pensamento econômico são capazes de apresentar formulações que dialoguem com a conformação espacial das cidades no capitalismo contemporâneo. Para isso, parte-se de uma apresentação dos pressupostos de um modelo neoclássico tradicional de Economia Urbana, seguido da apreciação crítica desse modelo. A partir dessa crítica, expõem-se as diversas visões das escolas de pensamento econômico em relação ao conceito de renda da terra, o qual é entendido como uma categoria de análise ainda útil para se entender tal estrutura espacial, bem como são fundamentais as considerações sobre as particularidades do urbano.

PALAVRAS-CHAVE: Renda da terra; Espaço Urbano; Economia Urbana; História do Pensamento Econômico; Economia Política.

ABSTRACT: This paper aims to expose and discuss which schools of economic thought are able of presenting formulations that dialogue with the spatial conformation of cities in contemporary capitalism. For this, it is based on a presentation of the assumptions of a traditional Neoclassical model of Urban Economics, followed by a critical appreciation of this model. From this critique, different views of the schools of economic thought are exposed in relation to the concept of land rent, which is understood as a category of analysis still useful to understand such a spatial structure, as well as the considerations about the particularities of the urban.

KEYWORDS: Land rent; urban space; Urban Economics; History of Economic Thought; Political Economy.

JEL Classification: B2; B24; R1; R14; P48.

\footnotetext{
* Doutorando em Economia pelo Centro de Desenvolvimento e Planejamento Regional da Faculdade de Ciências Econômicas da Universidade Federal de Minas Gerais (Cedeplar-FACE/UFMG). Gerente de Regulação Tarifária na Arsae-MG. E-mail: renanp.almeida@gmail.com E-mail: renanp.almeida@gmail. com; ralmeida@cedeplar.ufmg.br. Professor Associado do Cedeplar (FACE/UFMG) e do Núcleo de Pós-Graduação em Arquitetura e Urbanismo da Escola de Arquitetura da UFMG (NPGAU-EA/UFMG). E-mail: montemor@cedeplar.ufmg.br. Submetido: 4/maio/2015; Aprovado: 17/março/2016.
} 


\section{INTRODUÇÃO}

A tentativa de incluir o espaço na análise econômica perpassa pela necessidade de se fazer uso de conceitos, categorias e teorias que estabeleçam uma relação entre o espaço abstrato e as relações econômicas. Nesse sentido, na busca de referenciais para tentar explicar a morfologia e a dinâmica das cidades contemporâneas a partir da Ciência Econômica, pode-se vislumbrar duas grandes correntes de pensamento: aquelas relacionadas ao utilitarismo e aquelas fundadas sobre a teoria do valor-trabalho. A primeira dessas correntes elabora uma argumentação que gira em torno dos fundamentos de sua doutrina (o core da economia mainstream atual), com instrumentos heurísticos como "equilíbrio" e "maximização" sendo recorrentemente evocados. Por outro lado, os autores que consideram a teoria do valor-trabalho apresentam a cidade como palco de conflitos entre classes e setores, em uma estrutura que inexoravelmente se afasta do equilíbrio e cuja maximização "racional" economicista parece ser de pouca valia para explicar padrões.

Assim, este trabalho argumenta que os modelos derivados da tradição neoclássica e de equilíbrio geral não parecem ser capazes de dialogar com o espaço percebido e com o espaço vivido em nossas metrópoles - pelas características dos fenômenos espaciais e dos bens existentes no urbano ${ }^{1}$. Diante dessa constatação, retoma-se o conceito de renda da terra - que já possuía suas primeiras formulações desde os fisiocratas, mas só atinge uma clareza de definição, tal qual será adotado aqui, em Ricardo - enquanto arcabouço teórico para explicar a conformação das cidades contemporâneas. Desse modo, é apresentada uma visão crítica da Economia Urbana mainstream e uma possibilidade de se pensar o espaço urbano capitalista a partir de outro arcabouço teórico. Nesse panorama, argumenta-se que as cidades contemporâneas são mais bem caracterizadas pela diversidade de agentes (ou atores) que a habitam do que pelo pressuposto convencional de se considerar agentes homogêneos com funções utilidade idênticas. Além disso, também é discutido que a conformação espacial dessas cidades apresenta um padrão de dispersão e espraiamento ao longo do tecido urbano de tal maneira que torna frágil o pressuposto de que todos os empregos se concentram no centro de negócios da cidade - o chamado Central Business District (CBD). De fato, nota-se a degradação dessas antigas centralidades em várias partes do mundo e a ocupação dos subúrbios pelas elites em condomínios fechados, bem como a dispersão dos empregos nas indústrias localizadas nas periferias metropolitanas - e novos shopping centers em áreas cada vez mais distantes dos velhos centros. Assim, realiza-se uma crítica aos modelos que supõem que o preço e a renda da terra são mais altos no CBD e que decrescem a partir de um gradiente conforme se afasta desse ponto (modelos que seguem a tradição Alonso, Muth e Mills). Mesmo os modelos mais recentes de Economia

\footnotetext{
${ }^{1}$ Urbano é um termo tomado como sinônimo de sociedade urbana, seguindo diretamente a obra de Lefebvre (1999).
} 
Urbana que consideram estruturas urbanas policêntricas continuam jazendo sobre hipóteses frágeis sobre o urbano.

Diante dessa crítica, a alternativa teórica que se expõem concentra-se na retomada do conceito de renda da terra, a partir de autores como Ricardo, Lefebvre, Guigou, Lemos, e em especial, Marx e Topalov. A revisão da história do pensamento econômico, desde 1650 até os dias atuais, segue fundamentalmente o trabalho do francês Guigou (1982), obra não traduzida para o português (nem para o inglês). Essa referência permite constatações curiosas sobre o conceito de renda da terra na História do Pensamento Econômico (HPE), como a semelhança desse conceito nas obras de Ricardo e Marx no caso da renda diferencial; a originalidade do conceito de renda absoluta em Marx, que resolve o aparente paradoxo "a terra tem preço, mas não tem valor"; e as defesas ideológicas sobre o tema, muitas vezes surpreendentes, com economistas como León Walras sendo a favor da nacionalização do solo.

Dessa forma, além desta introdução, este trabalho é composto de uma seção que apresenta os pressupostos de um modelo convencional de Economia Urbana, seguido de uma apreciação crítica desses pressupostos a partir de seu confronto com a estrutura urbana das cidades contemporâneas. Na seção seguinte, o conceito de renda da terra é apresentado a partir de seu resgate na HPE. Então, esse conceito é mais bem detalhado e trazido para o caso urbano. Por fim, seguem as conclusões deste trabalho.

\section{APRECIAÇÃO CRÍTICA DA ECONOMIA URBANA E CIDADES CONTEMPORÂNEAS}

Nesta seção, busca-se estabelecer o padrão de sociedade urbana e a cidade contemporânea. A partir da exposição do modelo de Bruekner (1987), serão discutidos os pressupostos dessa classe de modelos diante do espaço urbano atual. Em seguida, são expostos alguns argumentos de Krugman (1995) sobre os “limites" da economia mainstream em suas tentativas de incorporar o espaço na análise-padrão.

A estrutura urbana que pode ser formada pela lógica dos modelos de inspiração neoclássica e de equilíbrio geral consiste, geralmente, de uma cidade com um CBD, conectado com outras partes do espaço por vias de transporte. Esse CBD em tese concentra a maior parte dos empregos e é a área de maior concentração de economias externas, possuindo, por isso, os mais altos preços e mais altas rendas no mercado imobiliário (terras urbanas e imóveis). A partir do CBD, os preços e a renda caem a partir de um gradiente ao longo das vias de transporte. Essa é a conformação urbana básica resultante de modelos inspirados nessa tradição (Alonso, 1964; Brueckner, 1987; Haig e McCrea, 1974; Krugman, 1995)².

Neste ponto, é considerado válido expor o modelo elaborado por Brueckner

\footnotetext{
${ }^{2}$ É importante notar como esses modelos possuem como inspiração mais profunda o trabalho de Von Thünen, de 1826, no qual o centro de uma vila em uma planície era a terra agrícola mais produtiva, e
} 
(1987), que pretende sintetizar os modelos de Mills e Muth. Esse modelo é apresentado com algum detalhamento, visando esclarecer as críticas que serão feitas a essa classe de modelos logo a seguir. Ele considera que todos os indivíduos possuem uma mesma função utilidade (estritamente quase côncava), ganham as mesmas remunerações por hora de trabalho e que todos os empregos se concentram no centro da cidade (CBD). Além disso, o conjunto de consumo dos indivíduos é direcionado a três itens: o custo de deslocamento (decorrente do custo de transporte por milha percorrida vezes a distância até o CBD); o custo de moradia (obtido pelo produto entre o custo do aluguel por unidade de espaço e a quantidade de espaço consumido); e os demais itens de consumo. A utilidade é extraída a partir do consumo dos outros bens e do espaço de moradia, isto é, a função utilidade contém dois argumentos - um relativo à moradia, e outro referente aos outros bens.

Dessa forma, o problema do consumidor se resume em maximizar sua utilidade diante de uma restrição orçamentária que é restrita pelo custo de moradia e de transporte, e dos outros bens. Após se igualar as condições de primeira ordem à restrição orçamentária, obtém-se uma solução em função dos parâmetros que representam o preço do aluguel e da quantidade de espaço para moradia consumido. A partir dessa solução, podem ser elaborados exercícios de estática comparativa, que visam elucidar o padrão das cidades contemporâneas - como a existência de prédios mais altos próximos aos centros e uma relação direta entre a altura dos edifícios e o tamanho do centro urbano.

Ora, as críticas a um modelo como esse saltam aos olhos. Considerar que todos os indivíduos possuem a mesma função utilidade parece ser um pressuposto bastante delicado para uma situação genérica, mas torna-se grosseiro para a diversidade de tribos e grupos sociais que compõem as sociedades urbanas. A diversidade é uma das características das cidades mais ressaltadas por diversos autores. Entre eles, vale destacar o trabalho de Jacobs (1969), que entende o dinamismo econômico das cidades a partir da capacidade de criação de trabalho novo e da fertilização cruzada de ideias. Storper e Venables (2004) também destacam a importância dessas interações entre as diferenças, a partir do que chamam de buzz feed effect - o burburinho das cidades que propicia as atividades criativas. Esses autores destacam também o papel dessas interações através do conceito de ativos intangíveis, como conhecimento, reputação e motivação, que se concentram nas aglomerações urbanas. Ainda, um conceito recorrente na Geografia Urbana é o conceito de alteridade, que se refere justamente à diversidade de atores, ideias, culturas, hábitos e preferências no ambiente urbano (Hall, 2000). A diversidade da sociedade urbana é tal que Furtado (2009) utiliza a palavra atores ao invés de agentes para lidar com tal estrutura.

Além disso, pressupor que todos os empregos se encontram no Centro também se mostra como um pressuposto frágil. Ora, não existem postos avançados de serviços ou indústrias nas cidades contemporâneas? Isto é, a indústria se localiza em geral nas periferias metropolitanas, processo que fez as cidades se estenderem

a partir dessa porção de terra, a produtividade decaía. A seguir, comentários são tecidos sobre a essência desse modelo e suas implicações. 
desmensuradamente através do tecido urbano (Lefebvre, 1999, 2001a; Monte-Mór, $2007,2014)$. Sobre os serviços, cada vez torna-se mais recorrente a presença de grandes aglomerações deles em áreas distantes das antigas centralidades, como na Barra da Tijuca no Rio de Janeiro, ou nas "Seis Pistas" em Belo Horizonte, ou o Alphaville em São Paulo, apenas para citar alguns casos próximos (Almeida, 2015).

Ainda, de um ponto de vista alinhado com a Economia Política, considerar que todos os indivíduos recebem a mesma remuneração por hora de trabalho no CBD também se apresenta como um pressuposto facilmente rejeitado. Mesmo que todos os membros da sociedade trabalhassem na mesma centralidade, a divisão social do trabalho continuaria a existir, remunerando de maneira diferenciada os agentes.

Ademais, essa análise desconsidera qualquer possibilidade de o indivíduo não escolher baseado nos custos de transporte e moradia, mas considerando aspectos familiares, antropológicos ou sociais. Assim, não capta os indivíduos que escolhem o local de moradia simplesmente porque se trata do seu bairro de nascimento, ou baseando-se na localização da escola dos filhos, ou considerando o status de uma região, dentre outras razões. Ou seja, a extensão da doutrina da maximização da utilidade diante de uma restrição orçamentária para o processo de escolha da moradia parece descaracterizar essa escolha - e, isso, para quando há escolha, em um espaço urbano marcado por favelas, cortiços e comunidades que passam ao largo de poderem se movimentar livremente em busca de moradia. Também, como expõe Smolka (1979), no mercado imobiliário, a própria estrutura da oferta pode influenciar demanda, de modo que um esquema convencional de oferta e demanda pode ser de pouca serventia para explicar esse tipo de mercado.

Portanto, esses modelos não parecem ser capazes de explicar vários aspectos das cidades contemporâneas, além de já ignorá-los a priori a partir da definição dos pressupostos para os modelos. Outro fenômeno urbano recorrente, pertinente ao mercado imobiliário, são os "saltos" que ocorrem nos preços e nas quantidades imobiliárias urbanas: a partir de certa área em que essas variáveis são consideravelmente altas, áreas contíguas têm preços profundamente mais baixos, e distanciando-se alguns ou muitos quilômetros, essas variáveis voltam a se tornar altas novamente. Ou seja, é como se o mercado imobiliário "saltasse" sobre áreas de preços baixos e criasse novas áreas nobres em pontos distantes da centralidade principal, ao invés dos preços caírem gradativamente de acordo com o distanciamento do CBD. Um possível contra-argumento para esta crítica é que em áreas mais distantes voltam a surgir economias externas. Entretanto, esse contra-argumento não especifica como as economias externas podem variar tão abruptamente, no caso de áreas vizinhas e tão díspares - muitas vezes, por questões de alguns metros ou quarteirões (Almeida, 2015). Também parece insuficiente para lidar com um espaço urbano marcado pela presença de favelas.

Além dessa questão dos "saltos", os modelos neoclássicos também parecem não explicar o caso da decadência dos centros das cidades, uma vez que esses seriam as áreas de maior preço da terra urbana - local onde se define o próprio CBD. Para essa crítica, um plausível contra-argumento é a suposta existência de economias de desaglomeração que superam as economias de aglomeração nessas áreas, mas esse mesmo argumento invalida a ideia de que todos os empregos possam se 
concentrar no CBD e que este seria o ponto no espaço urbano de maior preço e renda da terra. Neste caso, é importante reconhecer que modelos mais recentes vêm sendo elaborados para superar essa limitação em relação à monocentralidade das cidades, como o de Fujita e Ogawa (1982) e Henderson e Mitra (1996) - que consideram o fenômeno das chamadas Edge Cities, termo derivado da obra de Garreau (1991) para se referir às centralidades que surgem fora dos velhos centros de negócios (Krugman, 1995; Nadalin, 2011). Certamente, esses modelos mais recentes são muito mais realistas do que aqueles do padrão Alonso-Muth-Mills (AMM). Entretanto, também são elaborados sobre microfundamentos, funções de produção e funções de utilidade, e maximizações.

Outra deficiência dos modelos que têm suas raízes na obra de Von Thünen é claramente exposta por Lemos (1988). Este autor afirma que:

"Todos estes resultados, que podem ser obtidos a partir da generalização do modelo de Thünen, não escondem, porém, a deficiência teórica principal do próprio modelo. Embora possa ser generalizado, ganhando com isso maior poder analítico, o esquema de Von Thünen será, sempre, um modelo geral eminentemente desaglomerativo, e, enquanto tal, insuficiente para explicar a dinâmica espacial. A depender apenas deste esquema, o movimento do capital no espaço seria tipicamente desaglomerativo e descentralizador, tornando a distribuição das atividades econômicas dispersa e atomizada, ao mesmo tempo em que desapareceria a renda espacial. Na realidade, o movimento do capital no espaço é o resultado líquido de fatores desaglomerativos (sintetizados pelo custo de acessibilidade) e, principalmente, de fatores aglomerativos" (Lemos, 1988, p. 342, grifo meu).

Para o caso do equilíbrio geral, fica evidente a crítica que pode ser feita por não considerar as particularidades do bem "terra", já que se trata de um bem imóvel, irreprodutível, heterogêneo, não fungível (que não acaba ao ser consumido), que possui divisibilidade limitada (os lotes ou imóveis precisam ter um tamanho mínimo para cada uso) e cuja oferta pode influenciar a estrutura da demanda (Harvey, 1974; Plambel, 1987; Smolka, 1979; Topalov, 1979, 1984).

No caso da discussão teórica elaborada por Krugman (1995) sobre a "incapacidade" do mainstream incorporar o espaço em suas abordagens, a argumentação se pauta, fundamentalmente, na falta de ferramentas adequadas para lidar com a "economia espacial". Nesse sentido, Krugman (1995) acredita que a incapacidade de se modelar adequadamente os retornos crescentes à escala e mercados de competição imperfeita levaram aos economistas a ignorar as questões espaciais durante tanto tempo. Nos termos desse autor:

"And so how did the mainstream cope with spatial issues? By ignoring them. Never mind that the importance of location confronts us continually in daily life, or for that matter that urban systems exhibits regularities as strong as any in economics. [...] [E]conomists avoided looking 
at the spatial aspect of economies because they knew they had no way to model that aspect" (Krugman, 1995, p. 36-37).

Embora Krugman (1995) realize uma concisa e didática apresentação do que ele considera as "Cinco Tradições"3 da Geografia Econômica, sua argumentação se mostra substancialmente incauta em relação ao fato do mainstream evitar lidar com o espaço. Com vantagem da visão retrospectiva, nos 20 anos que se seguem a essa obra de Krugman (1995), foi desenvolvida uma pletora de modelos que lidam com retornos crescentes e competição imperfeita na Ciência Econômica, inclusive na tentativa de incluir o espaço, o que rendeu a Krugman até o Prêmio Nobel de Economia. Mesmo assim, a discussão sobre espaço continua fora dos livros textos de economia, e considerável parte da profissão continua a desconhecer mesmo uma abordagem mais convencional como a proposta por Krugman através da chamada "Nova Geografia Econômica".

Há uma dimensão epistemológica-ideológica que esse autor parece não levar em conta, com implicações dos conhecimentos de Economia Política no espaço. Conhecer, reconhecer e compreender o espaço urbano e regional implica ter que encarar dogmas que a ortodoxia insiste em não discutir: a ideia de equilíbrio, a maximização individualista, a homogeneidade dos agentes, a imobilidade dos fatores, a distinção entre tempo lógico e tempo cronológico e entre curto prazo e longo prazo, entre outros dogmas dessa tradição de pensamento. E abandonar esses dogmas leva a implicações fortes no fazer da política pública. Logo, o que é argumentado aqui é o mainstream não incorpora o espaço em seu curso-padrão por causa de questões mais ideológicas e dogmáticas do que por razões técnicas por falta de modelos, como pensava Krugman.

Dessa forma, a conexão que se vislumbra com a morfologia e fisiologia das cidades no capitalismo contemporâneo se dá com os trabalhos elaborados por autores neomarxistas ${ }^{4}$. Em geral, para os teóricos que trabalham sob essa perspectiva, as particularidades do bem "terra" ${ }^{5}$ são reconhecidas, assim como a relevância

\footnotetext{
${ }^{3}$ As cinco tradições expostas por Krugman são: Geometria Germânica; Física Social; Causação Cumulativa; Economias Externas Locais; Renda da Terra e Uso da Terra. Por "Geometria Germânica", o autor entende as obras de Alfred Weber, Christaller e Lösch, por tratarem da localização industrial em uma paisagem bi-dimensional. A expressão "Física Social" se refere ao uso de padrões de distribuição espacial, como a Lei de Zipf e o potencial de mercado e suas aplicações na Economia Regional. A interpretação de Causação Cumulativa é equivalente à dada no Desenvolvimento Econômico, muito embora nesse tópico Krugman (1995) dê pouca ênfase a Myrdal e Hirschman. As Economias Externas Locais são as típicas externalidades de aglomeração, nas quais o autor trata dos aportes de Marshall (e desconsidera a obra de Jane Jacobs). Por "Renda da Terra" e "Uso da Terra", Krugman (1995) significa as derivações do modelo de von Thünen, e claramente não entende a "Renda da Terra" da mesma maneira que é considerada neste artigo, ao desconsiderar a amplitude do termo e referir-se apenas a obras à la Von Thünen.

${ }^{4}$ Considera-se possível trabalhar essas questões a partir de uma abordagem neo-ricardiana também, embora essa pareça genérica demais para os aspectos da sociedade urbana, ao menos no escopo deste trabalho. Sobre essa possibilidade, ver Guigou (1984).

${ }^{5}$ As particularidades dos bens imóveis podem ser resumidas como: não-fungíveis; não plenamente
} 
da questão da propriedade e da distribuição do excedente entre grupos sociais. A renda da terra é uma formulação que aparece especificada na obra de Marx, que a desmembra e classifica de acordo com sua origem, além de sistematizar diferentes categorias de renda da terra e fornecer uma equação para o preço da terra. Nesse contexto, Lefebvre (2001a) destaca a importância da teoria da renda fundiária para a compreensão espaço urbano capitalista contemporâneo:

"A questão da renda fundiária parecia fora de moda; porém, ela conserva sua importância. Ela se amplia mesmo, pois os terrenos disponíveis para a construção da cidade industrial, seus preços, a especulação que se apossa deles, são do domínio dessa teoria, aparentemente marginal em relação à do lucro e do salário" (Lefebvre, 2001a, p. 162).

Assim, a renda fundiária pode ser entendida como um conceito capaz de superar algumas das limitações expostas anteriormente em relação a outras correntes do pensamento econômico. Essa renda não necessita de ser mais elevada no centro das cidades, desde que suas componentes (diferencial, absoluta e de monopólio, apresentadas a seguir) sigam outra configuração. Além disso, o conceito de renda da terra é elaborado simultaneamente com uma discussão referente à distribuição do excedente entre grupos sociais distintos, e considera fatores como a instituição da propriedade privada da terra e o status entre as diversas áreas no espaço. Dessa maneira, a renda da terra é capaz mitigar as questões da descontinuidade do espaço urbano e da diversidade de agentes e classes existentes. A partir dessas motivações, apresentam-se então aportes à teoria da renda da terra, categoria de análise e instrumento heurístico relegado pela tradição neoclássica ${ }^{6}$.

\section{HISTÓRIA DO PENSAMENTO ECONÔMICO E RENDA DA TERRA}

Apesar da potencial relevância do conceito de renda da terra para a explicação do mercado de moradia e da estrutura urbana, esse conceito vem sendo pouco usado desde os final dos anos 1980, o que difere do período imediatamente anterior, quando autores como Lipietz, Lojkine, Alquier, Fine, Harvey, Seabra e Topalov contribuíram substancialmente para o tema (Botelho, 2008). No caso brasileiro, pesquisadores como Pedro Abramo, Oscar Smolka, Fernanda Furtado, Sérgio Martins, Aluísio W. Ramos, Oscar Alfonso, Tamara C. Egler, Luiz Cesar Ribeiro Queiroz e Reinaldo A. Carcanlholo também contribuíram para o entendimento da renda fundiária (Botelho, 2008). Entender por que houve um considerável abandono da renda da terra desde os anos 1980 constitui uma pesquisa em si, que ultrapassa em muito o escopo deste artigo. O que é oferecido aqui é uma retomada do conceito, como recentemente vem

divisíveis (tamanho mínimo); suporte para a maior parte das atividades; imobilidade do capital; irreprodutibilidade da localização.

\footnotetext{
${ }^{6}$ Vale mencionar vários dos argumentos apresentados nesta subseção podem ser encontrados mais bem detalhados em Almeida (2015).
} 
sendo feito em autores como Botelho (2008) e Almeida e Monte-Mór (2011). Esta seção segue fundamentalmente a obra de Jean-Louis Guigou, obra não disponível em português nem em inglês, pelo que se sabe até o momento. Cabe mencionar que uma leitura mais simples, concisa e direta sobre a questão do espaço (e não da renda) na Economia pode ser encontrada em Krugman (1995).

Dessa forma, o conceito mais simplista de renda da terra pode ser enunciado como a renda do proprietário da terra, ao mesmo tempo em que pode ser entendida como o preço pago pelo locatário pelo direito de usar as faculdades produtivas do solo. Entretanto, tal definição pode ser vista como tautológica, uma vez que não diz nada a respeito da natureza e da origem de tal renda (Guigou, 1982).

Nesse sentido, as primeiras contribuições da ciência econômica para as questões da renda da terra e do uso do solo podem ser encontradas entre os anos de 1650 e 1810, em autores como William Petty, S. de Le Prestre de Vauban, Richard Cantillon, François Quesnay e Anne Robert Jacques Turgot, que podem ser englobados como fisiocratas, além dos clássicos Adam Smith e Robert Malthus. Embora esses autores apresentem diferenças significativas em suas obras como um todo, esses autores fisiocratas podem ser conectados por uma linha de pensamento, a qual é chamada por Jean-Louis Guigou (1982) de "fatalismo natural": a Natureza, isto é, Deus, era a origem de um produto agrícola líquido (geralmente excedente) e o Rei, pelo poder divino a ele concedido, recuperava esse excedente. A grande propriedade aristocrática era justificada da mesma forma. A partir dessas ideias, o conceito de renda da terra foi aparecendo lentamente, ficando mais claro em Smith e Malthus (Guigou, 1982).

A partir do início do século XIX, dentro da Economia, emergiram visões profundamente diferentes da apresentada no parágrafo anterior, e a renda da terra ganhou abordagens específicas. Para Ricardo e Marx, as questões da renda da terra e do uso do solo deviam ser entendidas no contexto do processo de desenvolvimento agrícola, sendo que a teoria da renda da terra nesses dois autores é fundada sobre a teoria do valor-trabalho. Nesse caso, a renda é uma parcela apropriada do excedente coletivo gerado pelo trabalho, criando aí o conflito entre salários, lucros (que também querem se apropriar do excedente) e renda. Com o parcelamento do solo, o relativo desaparecimento da classe dos grandes proprietários de terras na Europa e a diminuição das diferenças "naturais" de fertilidade, a análise nessa linha teórica passou a lidar com a questão urbana ao longo do século XX. Emergiram temas como a especulação imobiliária e o parcelamento, e a sociologia e a história passaram a contribuir para o debate. Além de Ricardo e Marx, podem ser agrupados nessa linha de pensamento autores como Denis Barthélemy, Jean-Pierre Boinon, Robert Baudoin, e Henri Lefebvre (Guigou, 1982; Harvey, 2006).

Essa linha de pesquisa é, de certa maneira, retomada e refinada por autores neorricardianos e neomarxistas, a partir dos anos 1960. Em geral, nessas visões, pode-se entender que a terra é, ela mesma, uma produção social. A produção de commodities agrícolas é vista como produto do capital agrário, e a produção da habitação aumenta o produto agregado da sociedade e valoriza o terreno sobre o qual é construída. Através da circulação do sistema econômico, a renda aparece, podendo ser agrícola ou urbana. Ademais, alguns autores se afastam da concepção 
naturalista de Ricardo e Marx, segundo a qual a terra é um recurso natural e a renda possui origem na escassez física e na heterogeneidade das terras (hipótese chamada de exogeneidade da renda). Essa exogeneidade da renda da terra é negada ao menos em alguns casos, como em espaços de intensa produção industrial e de significativa urbanização. Entre neomarxistas e neorricardianos, a diferença básica é que os primeiros abarcam contribuições sociológicas a partir do entendimento das classes sociais, enquanto os segundos realizam uma análise mais essencialmente econômica. Entre os autores desses dois grupos, é possível destacar os neorricardianos Piero Sraffa e Jean-Louis Guigou, e os neomarxistas Allen Scott, Alain Lipietz e Christian Topalov (Guigou, 1982).

Paralelamente a essas linhas de pensamento apresentadas, desenvolveu-se uma teoria de localização das atividades econômicas, tendo como ponto mais profundo uma concepção cartesiana da ciência econômica. A evolução da teoria nesse domínio é bem clara: começa com os primeiros modelos de Von Thünen, em 1826, nos quais a renda resulta das economias de transporte e das terras mais bem localizadas, que ficam no centro da vila em uma planície - era o "Estado isolado" de Von Thünen. Essas terras desfrutam de uma renda de situação em relação àquelas que são mais distantes. Nas análises mais recentes e sofisticadas, o espaço é organizado pela lógica das "economias externas" (que atuam como forças de "aglomeração" e "desaglomeração"), produzidas pelo ambiente no qual se localiza a atividade. Dessa forma, o conceito ganha generalidade, mas perde em precisão, uma vez que é difícil medir as economias externas. Apesar desse ganho de generalidade, ao longo do século XX os economistas que seguem essa linha teórica continuaram a considerar um ponto central tido como o mais privilegiado - tendo o centro da vila de Von Thünen sido substituído pelo CBD. Podem ser agrupados, nessa corrente, autores como Alfred Marshall, Auguste Lösch, Edgar Dunn, William Alonso, Edwin Mills e Richard Muth (Guigou, 1982).

Com uma concepção filosófica semelhante aos teóricos da localização das atividades, a questão da terra também é estudada à luz dos modelos de equilíbrio geral. Nesse caso, a ideia central é que a terra é um bem econômico ordinário qualquer, que possui uma utilidade associada, assim como um preço. Logo, são as leis de mercado que decidem sua alocação entre os agentes, e a renda da terra é um preço de um fator de produção. Nessa tradição, podem ser agrupados autores como Jean-Baptiste Say, Carl Menger, Léon Walras, Jonh Clark, Maurice Allais e Edward Chamberlin (Guigou, 1982).

Contudo, as questões da renda da terra e do uso do solo são tão polêmicas e paradoxais que diversos autores as discutiram não sob a perspectiva de uma escola de pensamento específica, mas de uma perspectiva sobre a socialização do solo em si. Isto é, nesse tema, a politização e a existência de uma práxis se fazem assaz presentes. Para esse agrupamento de autores, os argumentos elaborados se referem a indagações como: A propriedade privada da terra, com suas vantagens em relação à eficiência econômica e desvantagens distributivas, é justificável? Quais são os obstáculos à socialização do solo? Em que sentido a terra pode ser diferente de outros bens como o ar e água? (Guigou, 1982).

Aqui, opiniões e posições surpreendentes emergiram, com autores como Léon 
Walras (vinculado aos utilitaristas) defendendo radicalmente a nacionalização do solo, e com marxistas sendo mais reservados. Dentre esses autores, por exemplo, alguns entendiam que a terra deveria ser organizada em pequenas comunidades camponesas. Nesse debate, as percepções de liberais e socialistas convergem, por condenar o enriquecimento sem causa - obtida através da simples instituição da propriedade, fundada, por sua vez, na instituição da herança. Tanto do ponto de vista dos primeiros quanto dos segundos, o "adversário" ideológico fica claro: as antigas aristocracias, possuidoras de uma propriedade que é entendida como obstáculo tanto para o capital quanto para a emancipação dos trabalhadores. Entre os autores que tratam dessa temática estão Pierre J. Proudhon, Jonh Stuart Mill, Henri George, Léon Walras, Vilfredo Pareto, Lênin, Edgard Pisani, Philippe Lamour, Jean-Pierre Gilli (Guigou, 1982).

\section{RENDA FUNDIÁRIA E RENDA FUNDIÁRIA URBANA}

Diante do panorama apresentado na seção anterior, a teoria da renda da terra urbana é apresentada neste artigo, tendo como base autores como Ricardo e Marx, além de Lemos (1988) e Topalov (1973) apud Guigou (1982), entre outros. São explicados os conceitos de renda diferencial I, renda diferencial II, renda de monopólio e renda absoluta.

Nesse sentido, os conceitos de renda da terra aqui apresentados tem suas raízes, em especial, no Livro 3, Tomo III, de "O Capital", de Marx. Esses conceitos e a apreciação crítica realizada sobre eles tem como fonte principal a obra de Guigou (1982). Uma atualização desses conceitos é feita a partir das obras de Harvey (2006), Lemos (1988) e Topalov (1973).

Em Marx, a terra é um recurso natural que não possui valor, uma vez que todo valor vem do trabalho. A terra, assim como o ar e a água, é vista como uma condição natural de produção. Dessa forma, os problemas relacionados à terra não decorrem da relação terra-homem, mas das relações entre as classes. Por isso, a renda da terra não é entendida como a remuneração de um fator, como preconiza a teoria neoclássica, mas o pagamento pelo uso de um direito (ideia retomada claramente em Lieptz). Essa renda é extraída do sobrelucro, e pode ser paga em trabalho, em produto ou monetariamente (Guigou, 1982; Harvey, 2006).

Como argumenta Lefebvre (2001a) sobre a questão da propriedade fundiária na obra de Marx,

“A propriedade da terra se mantém no quadro da propriedade privada em geral. Ainda que essa propriedade imobiliária tenha dado lugar à propriedade mobiliária, dinheiro e capital, ela persiste. E mesmo ela se consolida, desde o tempo de Marx, a burguesia enriquece comprando terras, constituindo para si propriedades fundiárias (e, consequentemente, reconstituindo, sobre a base de um novo monopólio, a propriedade fundiária e a renda da terra). A propriedade da terra, no fundo intacta, reconstituída pelo capitalismo, pesa sobre o conjunto da sociedade". (Lefebvre, 2001a, p. 160, grifo do autor). 
Abdicando de expor alguns dos principais conceitos da economia marxiana por uma questão de escopo, apresenta-se como Marx definiu os três componentes para a renda: a renda diferencial (RD), a renda absoluta (RA) e a renda de monopólio. Essas definições foram retiradas de Guigou (1982).

I. Renda Diferencial: decorre da captação de parte da mais-valia. Tem como fonte diferentes condições de produção, exógenas, que levam a produtividades distintas. Essa renda não afeta os preços dos bens agrícolas, que são dados pelo preço de produção do pior terreno (o terreno marginal incorporado à produção). A RD pode ser divida em renda diferencial I (RD-I) e renda diferencial II (RD-II).

II. Renda Diferencial I (RD-I). A RD-I tem como causa diferenças de fertilidade e localização do solo. Devido a essas diferenças, quantidades iguais de capital levam a rendimentos diferentes ao longo do espaço. É importante notar que essa definição é essencialmente igual àquela apresentada em 1815 por David Ricardo, o qual também utiliza a expressão "renda diferencial I" para descrever esse tipo de renda "extensiva", que decorre da incorporação de terrenos marginais. Sobre esse curioso e pouco observado ponto da história do pensamento econômico, Guigou (1982) chega a afirmar que a renda diferencial I é uma "infiltração marginalista" na obra de Marx.

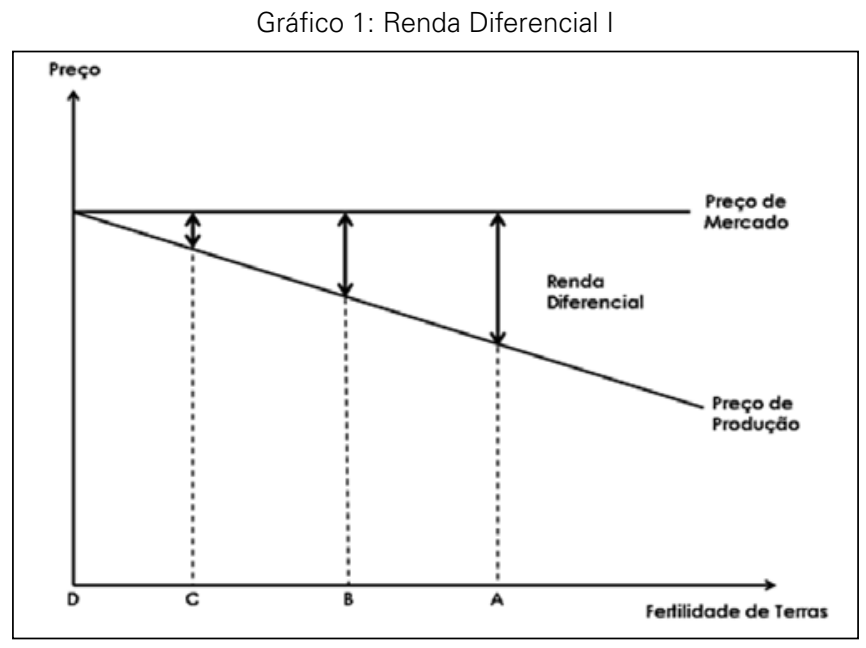

Fonte: Guigou (1982, p. 191).

III. Renda Diferencial II (RD-II). A RD-II decorre da quantidade de capital empregada sobre uma terra já utilizada. Quantidades diferentes de capital aplicadas a terras homogêneas levam a diferenças de produtividade, à semelhança da lei dos rendimentos marginais decrescentes - muito embora essa lei não apareça explicitamente em Marx. Em outras palavras, conforme se intensifica a produção sobre uma porção do espaço específica, as quantidades adicionais de capital levam a rendimentos diferentes, 
o que proporciona uma renda adicional à RD-I. Essa renda adicional é a RD-II. Enquanto a RD-I representa um caso de produção extensiva, a RD-II decorre de um processo intensivo, no qual quantidades diferentes de capital são empregadas em terras homogêneas.

IV. Renda Absoluta (RA). A RA decorre do fato do produtor marginal também ter um ativo, que gera uma renda. Para que a RA exista, uma condição é necessária: a composição orgânica do capital ${ }^{7}$ no setor agrícola tem que ser menor que nos outros setores da economia. Assim, esse setor emprega relativamente mais mão de obra e possui valor mais alto, uma vez que todo valor vem do trabalho. É esse valor mais alto que proporciona a RA. Portanto, há uma causa para a RA: a diferença entre as composições orgânicas do capital entre os setores não permite que os lucros entre eles se igualem. Isso reflete a influência sobre o pensamento de Marx (e também de Malthus e Ricardo) do fato dos alimentos terem preços mais altos que outros bens na Inglaterra do século XIX. Diante disso, os capitalistas precisavam pagar salários mais altos para garantir a sobrevivência do proletariado, o que evidencia o papel da propriedade privada do solo como um obstáculo ao capital. Nesse sentido, é importante destacar que a RA incide sobre os preços dos produtos agrícolas e faz com que estes sejam mais altos que os preços de produção.

Destarte, a Renda da Terra (R) é definida, até aqui, pela equação (1). O Gráfico 2 ilustra essa definição.

$$
\mathrm{R}=(\mathrm{RD}-\mathrm{I}+\mathrm{RD}-\mathrm{II})+\mathrm{RA}
$$

\section{Gráfico 2: Renda Diferencial e Renda Absoluta}

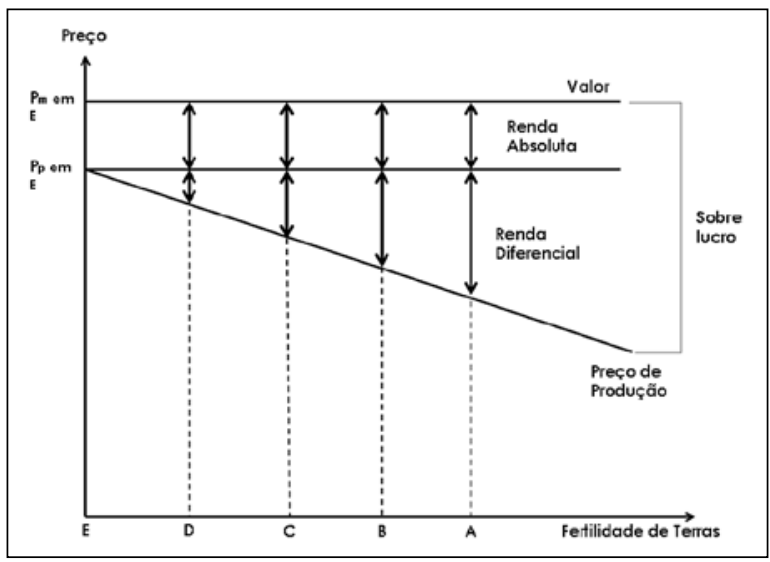

Fonte: Guigou (1983 p. 241).

\footnotetext{
${ }^{7}$ A composição orgânica do capital pode ser definida pela razão entre a parte do investimento destinado aos salários (s) e a parte destinada aos bens de capital (c), logo, c/s.
} 
Diante disso, o preço de venda do solo é a soma atualizada das rendas, isto é, o preço é formado pelo que contemporaneamente é chamado de "Valor Presente Líquido" (VPL) das rendas. Em Marx, isso significa que o comprador não adquire um bem ordinário, mas um direito de receber a renda. Essa é a explicação para o aparente paradoxo "a terra não tem valor, mas tem preço". Logo, o preço da terra pode ser descrito por:

$$
\mathrm{P}_{\mathrm{s}}=\frac{R_{1}}{(1+i)}+\frac{R_{2}}{(1+i)^{2}}+\ldots+\frac{R_{n}}{(1+i)^{n}}=\sum_{j=1}^{n} \frac{R_{j}}{(1+i)^{j}}
$$

na qual Ps é o preço do solo, $\mathrm{Rj}$ é a renda esperada para o j-ésimo período de tempo, e $i$ é a taxa de juros real da economia (que, a rigor, pode variar ao longo do tempo, mas por parcimônia, foi mantida constante na equação (2).

i. Renda de Monopólio. A Renda de Monopólio nasce das condições de demanda, como a escassez de certos produtos e o poder de compra dos consumidores. Ela se situa acima do valor, elevando o preço de mercado.

Gráfico 3: Renda Diferencial, Renda Absoluta e Renda de Monopólio

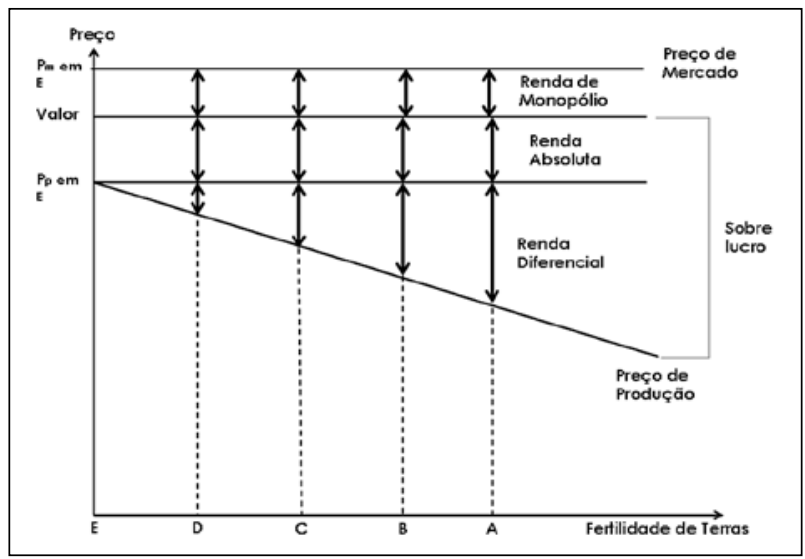

Fonte: Guigou (1982, p. 242).

Sobre a Renda de Monopólio, a seguinte explicação de Harvey (2006) pode ser adicionada:

"Circunstâncias às vezes emergem, entretanto, nas quais condições competitivas não prevalecem. Rendas de monopólio podem então serem percebidas. [...]. Localizações de prestígio e status criam todos os tipos de possibilidades de receber a renda de monopólio de outras facções da burguesia, por exemplo" (Harvey, 2006, p. 350).

Nesses termos, a Renda de Monopólio pode ser instrumental teórico útil para compreender elevados preços da terra em áreas remotas, porém provedoras de 
status para seus moradores. Este pode ser interpretado como o caso de condomínios e alguns bairros de elite dentro do espaço intraurbano.

Assim, a equação (1) pode ser reescrita, incluindo a renda de monopólio a ela:

$$
\mathrm{R}=(\mathrm{RD}-\mathrm{I}+\mathrm{RD}-\mathrm{II})+\mathrm{RA}+\mathrm{RM}
$$

Da mesma forma, quando se considera o preço do solo, definido na equação (2), pode-se incluir a Renda de Monopólio, o que leva a equação (2) a incorporar os quatro tipos de renda descritos na obra de Marx.

Dessa forma, após apresentar a contribuição marxiana para a renda da terra, é necessário trazer o conceito de Renda da Terra para o domínio urbano, já que Marx o tratou apenas no contexto agrário. Almeida e Monte-Mór (2011) afirmam que, segundo Harvey (1973), a transição do caso rural para o caso urbano não apresenta grandes desafios, por ser um conceito bastante geral. Senão, vejamos.

A partir da discussão da questão da renda da terra em Marx, Lefebvre (2001a) expõe essa transição conceitual da renda agrícola para a renda urbana, e destaca a importância desses conceitos para o entendimento do que ele chama de "teoria do ramo imobiliário".

“Isto quer dizer que a teoria do 'ramo imobiliário' [...] durante longo tempo setor secundário, progressivamente integrado ao capitalismo, está ainda em processo de elaboração. Esta teoria (crítica) trata precisamente do processo de integração, de subordinação ao capitalismo, de um setor por longo tempo exterior, solidariamente, com a integração da agricultura inteira (salvo as periferias), à indústria e ao capitalismo" (Lefebvre, 2001a, p. 167, grifo meu).

Lemos (1988) oferece uma visão particular da renda da terra urbana, relacionando-a principalmente aos serviços (bens non-tradables) urbanos. Aqui, tem-se uma visão estritamente econômica, na qual a renda é gerada à parte dos fatores de aglomeração e desaglomeração dos centros urbanos. Essa visão emerge de seu estudo sobre o movimento do capital no espaço, no qual a renda da terra é vista como um instrumento heurístico para a compreensão da "Renda Espacial" (renda urbana), que é considerada mais complexa do que a renda no caso agrícola. Esse autor procedeu a um retorno a Marx, por entender que as vantagens naturais de Ricardo, que justificam a Renda Diferencial, não são suficientes para explicar todo o processo de formação da renda. Por isso, também considera fundamental o conceito de Renda Absoluta de Marx, assim como é feito neste trabalho.

Embora trate da localização das atividades econômicas, e por isso não trate diretamente da questão residencial, Lemos (1988) oferece uma visão importante do urbano. Essa ótica retoma a contribuição de Castells, que entende o espaço urbano a partir do consumo coletivo ${ }^{8}$. Lemos (1988) estende essa noção de consumo para todo ato de compra e venda, inclusive de mão de obra e meios de produ-

\footnotetext{
${ }^{8}$ Castells foi criticado nesse ponto por autores que entendem o urbano em especial a partir das condições gerais de produção, como Topalov e Lojkine. Sobre isso, ver Monte-Mór (2007).
} 
ção, de tal forma que quando se fala em "acessibilidade a um mercado", na verdade trata-se de acessibilidade a um centro urbano. Em outras palavras, "o que definimos como 'mercado' é sinônimo, puro e simples, do 'urbano', constituindo uma área (mercado) com centro num núcleo produtor de serviços de consumo e de circulação" (Lemos, 1988, p. 346).

Nesse contexto, a conformação espacial das cidades pode ser explicada pelo conflito entre capital e renda, tendo a renda uma interpretação semelhante a um "custo" sobre a produção. Por isso, esse autor afirma que "[...] enquanto que a existência do sobrelucro constitui, por si, um fator de atração do capital, sua conversão em renda fundiária constitui um fator de repulsão, configurando um movimento contraditório" (Lemos, 1988, p. 06, grifo meu).

Portanto, a aglomeração urbana para esse autor se justifica pela "lei geral" da escala e da produtividade, e especialmente, pela natureza do setor terciário, que fornece produtos que não podem ser transportados, como é o caso dos serviços. Nesse setor, o capital fixo representa uma parcela significativa do próprio capital produtivo, inclusive através da infraestrutura pública. Isso permite a cristalização de ativos nas centralidades. Por outro lado, a depreciação desses ativos seria a explicação para a degradação desses espaços. A renda da terra urbana atua como um dos motores da dispersão da metrópole, uma vez que sua existência representa um custo adicional à presença das atividades econômicas na aglomeração urbana, como argumentado no parágrafo anterior ${ }^{9}$ (Almeida, 2015; Lemos, 1988).

Por outro lado, Topalov (1973) apud Guigou (1982) retoma a contribuição de Marx para o assunto no intuito mais específico de atualizar aquele trabalho para o ambiente urbano contemporâneo. Assim, aquele autor considera que o solo não é um bem em si, mas é um suporte indispensável para a definição do capital construído, e que a propriedade - e a pluralidade social - são obstáculos ao sobrelucro e à expansão do capital. Nesse autor, a produção de moradia constitui a forma mais avançada de desenvolvimento das forças produtivas no setor da construção e das obras públicas - uma vez que ela envolve todos os agentes expostos no Esquema 3, além de estar sujeita a todos os tipos de renda da terra, em especial a de monopólio Nessa obra de Topalov, a propriedade fundiária possui três abordagens:

a) ideológica, que separa proprietários de não proprietários;

b) jurídica-política, uma vez que o direito de propriedade é definido em lei. Nesse caso, entende-se que o direito evolui conjuntamente com a sociedade, de tal forma que o Estado, que garante a propriedade, passa a interferir sobre ela pela política urbana com zoneamentos, lei de usos e

\footnotetext{
${ }^{9}$ É curioso pensar, nesses termos, que a renda é causada pela aglomeração, ao mesmo tempo em que causa efeitos sobre a dispersão.
} 
ocupação do solo, entre outros instrumentos, de modo a opor Estado e proprietários;

c) econômica, uma vez que a renda é resultante da relação de produção entre o trabalhador e o proprietário fundiário. Vide Esquemas 1 e 2.

Essas três abordagens se ligam, pois com o avanço do modo de produção capitalista, o capital (através do Estado) vai diminuindo o poder dos proprietários, fazendo com que, no limite, ele mesmo seja o proprietário. Dessa maneira, o capital incorpora a renda no processo de acumulação ${ }^{10}$ - nessa lógica, a partir da compra de terras pelos capitalistas, o que contemporaneamente pode ser instrumentalizado através de mecanismos financeiros como fundos de investimentos, certificados de recebíveis imobiliários, e ações das sociedades anônimas que atuam no setor imobiliário e incorporador. Os Esquemas 1, 2 e 3, a seguir, ilustram essas relações de produção e repartição.

Esquema 1: Relação entre Proprietários Fundiários

e Trabalhadores Agrícolas

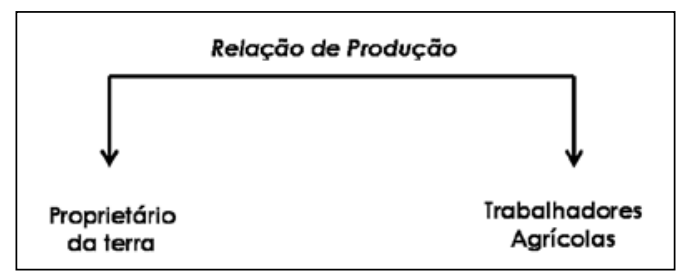

Fonte: Guigou (1982, p. 667).

Esquema 2: Relação entre Proprietários Fundiários, Trabalhadores Agrícolas e Fazendeiros

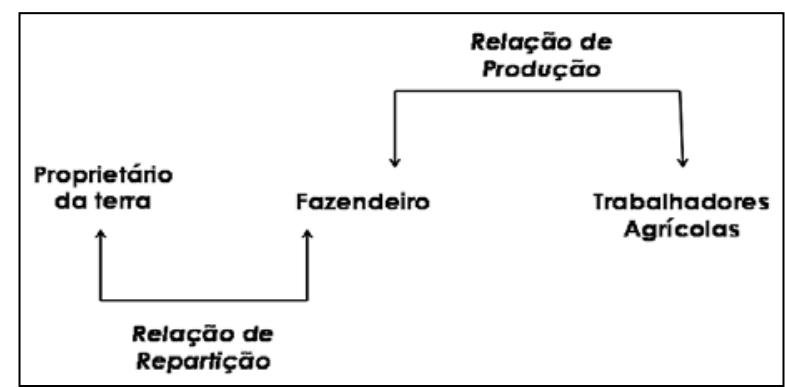

Fonte: Guigou (1982, p. 668).

\footnotetext{
${ }^{10}$ Nota-se que esse argumento supera a limitação aparente da obra de Marx, que mostrava lucros declinantes - fato que, mais de cem anos depois de O Capital, quando Topalov escreveu, ainda não dava claros sinais de que estava acontecendo.
} 
Esquema 3: Relação entre Proprietários Fundiários, Trabalhadores da Construção Civil, Construtores, Setores Financeiros e Incorporadores (Caso Urbano)

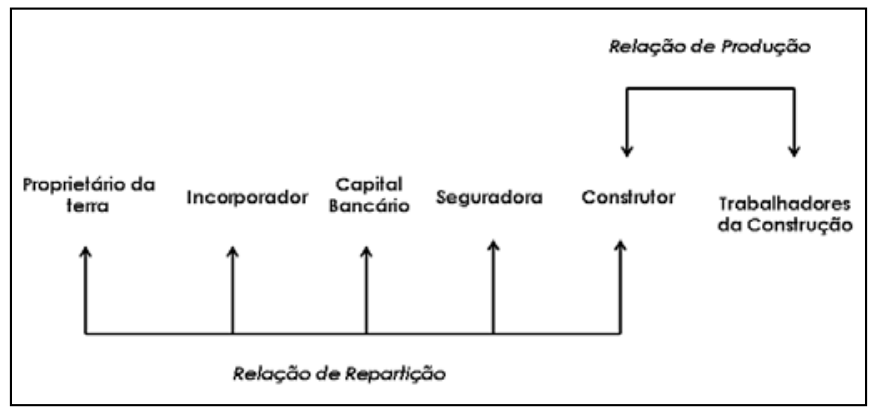

Fonte: Guigou (1982, p. 670).

Dentre as categorias de renda, Topalov (1973) apud Guigou (1982) retoma as mesmas categorias de Marx (renda diferencial, renda absoluta, e renda de monopólio). Entretanto, a renda fundiária pura tende a se desintegrar, conforme passa a integrar uma categoria mais geral de outros objetos de monopólio (patentes e investimentos em capital fixo, e outras formas de acumulação do capital). Essa reinserção no processo de acumulação faz com que mais atores passem a tomar parte da mais-valia fundiária. Esse número maior de atores reflete a própria complexidade do urbano, como pode ser visto no Esquema 3.

Assim, os capitalistas captam parte da renda que antes ia para os proprietários e a reinserem no processo de acumulação, levando os rentistas individuais a desaparecem gradativamente e serem substituídos por especuladores institucionais. Esse autor esboça uma ordem cronológica dos eventos, como mostram as seguintes fases (Almeida, 2015; Guigou, 1982).

$\left.1^{a}\right)$ A propriedade fundiária exógena gera a renda fundiária tradicional;

$\left.2^{a}\right)$ a luta entre capitalistas e proprietários fundiários gera as rendas fundiárias tais quais analisadas por Ricardo e Marx;

$\left.3^{a}\right)$ o capital monopolista cria outros tipos de rendas, que compensam a tendência de baixa do lucro, como patentes e monopólios;

$4^{a}$ ) o Estado (por meio de regulação, expropriação etc.), capturado pelo capital, limita as rendas fundiárias tradicionais;

$\left.5^{a}\right)$ no limite, o capital se apropria do solo e do produto, para confiscar as rendas.

Assim, embora se reconheçam eventuais simplismos e a dificuldade operacional dos termos elaborados na obra de Topalov, entende-se que ela é uma referência importante para a compreensão do espaço urbano capitalista contemporâneo. Essa importância se releva por especificar o processo de geração da renda fundiária urbana (de onde são derivados os preços dos imóveis, a partir da capitalização) e se expor esquematicamente os atores e as relações entre eles nesse mercado. Além 
disso, Topalov atualiza de maneira clara as contribuições de Marx (e Ricardo, indiretamente ${ }^{11}$ ) para o caso urbano.

\section{CONCLUSÕES}

Este trabalho visou apresentar uma discussão sobre a pertinência da análise de um grupo de autores e a relação dessa análise com as cidades no capitalismo contemporâneo. Nesse sentido, a apreciação crítica se fez basicamente ao confrontar as estruturas e dinâmicas das cidades contemporâneas e os pressupostos teóricos dos modelos neoclássicos de Economia Urbana. Nomeadamente, os fundamentos necessários para a dita maximização de utilidade dos agentes no ambiente urbano parecem frágeis e de pouca representatividade da sociedade sobre a qual se referem. Nesse sentido, pressuposições como a homogeneidade das preferências entre os agentes, a obtenção da mesma remuneração por hora trabalhada, a concentração absoluta e total das atividades econômicas nos centros das cidades, a continuidade ininterrupta dos preços e rendas ao longo do espaço e desconsiderações de aspectos sociais e antropológicos tornam essa abordagem pouco verossímil.

Então, apresentou-se uma revisão da ciência econômica sobre o espaço e do conceito de renda da terra, à luz da história do pensamento econômico. Essa leitura permitiu conectar autores que mostram entre si similitudes sobre essa temática, e delinear ao menos dois grandes grupos de autores nesse escopo: aqueles que aplicam os pressupostos do core neoclássico à economia no espaço; e aqueles que, a partir da teoria do valor-trabalho, utilizam o conceito de renda da terra e reconhecem a especificidade do objeto de estudo no caso da economia urbana. A escolha deste artigo foi por retomar a obra de autores que advinham da tradição da teoria do valor-trabalho e usavam o conceito de renda da terra.

A partir dessa revisão, buscou-se então esclarecer o conceito de renda fundiária, primeiro para o caso agrícola, tal como exposta por Ricardo e Marx, e em seguida para o caso urbano. Além disso, buscou-se adicionar à teoria da renda da terra elementos que consideram a complexidade de relações sociais das cidades, $\mathrm{o}$ que foi feito fundamentalmente a partir da obra de Topalov. Portanto, dois constructos teóricos se apresentaram como alternativa para a compreensão das relações econômicas no espaço urbano atualmente: a teoria da renda fundiária urbana e as relações de produção entre os atores que compõe essas sociedades. Esses dois constructos apresentaram-se assim como instrumentos que podem ser retomados em trabalhos posteriores para análises da realidade urbana e suas relações econômicas.

\footnotetext{
${ }^{11}$ Diz-se indiretamente em relação a Ricardo, pois o conceito de renda diferencial em Marx é essencialmente idêntico ao desse autor, sendo que Ricardo o descreveu décadas antes. O que Marx acrescentou ao trabalho de Ricardo foi o conceito de renda absoluta, fundamental para resolver o aparente paradoxo “a terra tem preço, mas não tem valor”. Ver Almeida, 2015; Guigou, 1982.
} 


\section{REFERÊNCIAS BIBLIOGRÁFICAS}

Almeida, L. F. G. DE; Monte-Mór, R. L. M. (2011) "Renda Fundiária e regulação imobiliária: dos aspectos teóricos à (quase) prática do Estatuto das Cidades. In: Estado e Capital Imobiliário. Belo Horizonte: Editora Com Arte.

Almeida, R. P. (2015) Implosão e explosão na exópolis: evidências a partir do mercado imobiliário da RMBH. Dissertação de Mestrado - Belo Horizonte: Universidade Federal de Minas Gerais.

Alonso, W.(1964) Location and Land Use. Cambridge, MA: Harvard University Press.

Alquier, F. (1971) "Contribution à l'étude de la rente foncière sur les terrains urbains. Espaces et Sociétés. 2 (80): p. $75-87$.

Botelho, A. (2008) "A renda fundiária urbana: uma categoria de análise ainda válida”. GEOgraphia (UFF), v. 19, p. 23-40.

Brueckner, J. (1987) “The structure of urban equilibria: a unified treatment of the Muth-Mills model”. In: Handbook of Regional and Urban Economics. North Holland, Amsterdan: Elsevier Science Publishers B.V., p. 821-845.

Furtado, B. A. (2009) Modeling social heterogeneity, neighborhoods and local influences on urban real state prices. Tese de Doutorado - Belo Horizonte: UFMG.

Guigou, J. L (1982) La Rente Fonciere. Paris: Economica.

Haig, R. M.; McCrea, R. C. (1974) Major economic factors in metropolitan growth and arrangement : a study of trends and tendencies in the economic activities within the region of New York and its environs. New York: Arno Press, v. 1

Hall, S. (2000) A identidade cultural na pós-modernidade. 4. ed. Rio de Janeiro: DP\&A.

Harvey, D. (1974) "Class-monopoly rent, finance capital and the urban revolution. Regional Studies": The Journal of the Regional Studies Association, v. 8, n. 3-4, p. 239-255.

Harvey, D.(2006) Limits to Capital. 3. ed. New York: Verso.

Jacobs, J. (1969) The Economy of Cities. New York: Random House,.

Krugman, P. (1995) Development, Geography, and Economic Theory. 1. ed. Cambridge, MA: MIT Press.

Lefebvre, H. (1999) A Revolução Urbana. Belo Horizonte: Editora UFMG.

Lefebvre, H.(2001a) O Direito à Cidade. 5. ed. São Paulo: Centauro.

Lefebvre, H. (2001b) A Cidade do Capital. 2. ed. Rio de Janeiro: DP\&A.

Lemos, M. B. (1988) Espaço e capital: um estudo sobre a dinâmica centro x periferia. Tese de Doutorado - Campinas: IE/Unicamp.

Lojkine, J. (1981) O Estado Capitalista e a Questão Urbana. São Paulo: Martins Fontes.

Monte-Mór, R. L. M. (2007) "Cidade e campo, urbano e rural: o substantivo e o adjetivo" In Feldman, S.; Fernandes, A. O Urbano e o Regional No Brasil Contemporâneo: Mutações, Tensões, Desafios. 1a. ed. Salvador: EDUFBA, p. 93-114.

Monte-Mór, R. L. M. (2014) "What is the urban in the contemporary world? In Brenner, Neil, ed. Implosions/Explosions: Towards a Study of Planetary Urbanization. Berlin: Jovis. p. 576.

Nadalin, V. G. (2011) Economia Urbana e Mercado de Habitação. In: Economia Regional e Urbana: Teorias e métodos com ênfase no Brasil. Brasília: Ipea, p. 221-258.

Plambel. (1987) O Mercado de Terras na Região Metropolitana de Belo Horizonte. Belo Horizonte: Plambel.

Smolka, M. O. "Preço da terra e valorização imobiliária urbana: esboço para o enquadramento conceitual da questão”. Ipea, Dezembro 1979. Disponível em: <http://www.ipea.gov.br/portal/index. php?option=com_content\&view=article\&id=2054>. Acesso em: 5 set. 2014

Storper, M.; Venables, A. J. (2004) “Buzz: face-to-face contact and urban economy.” Journal of Economic Geography, v. 4, p. 351-370.

Topalov, C. (1979) La Urbanización Capitalista. México, DF: Edicol.

Topalov, C. (1984) Ganancias y Rentas Urbanas. Madrid: Siglo XXI. 